\title{
Tomographic evaluation of TMJ in adolescents with temporomandibular disorders
}

\section{Avaliação tomográfica da ATM em adolescentes com disfunção temporomandibular}

\author{
Luciano José Pereira* \\ Maria Beatriz Duarte Gavião**
}

\begin{abstract}
This study evaluated the TMJ images of normal subjects and of those who presented TMD (temporomandibular disorders) using linear tomography at rest position. Craniomandibular Index (CMI) and a questionnaire on subjective symptoms were used to assess 217 subjects aged 12 to 18 years. Those with the highest and the lowest scores were divided into Control $(n=20)$ and TMD groups $(n=20)$, respectively. Corrected tomography was used to measure the narrowest anterior, superior and posterior joint spaces, to determine the condyle position in all 40 subjects. The distance means did not correlate with CMI scores ( $p>0.05)$. The number of posteriorly positioned condyles was significantly higher in TMD patients $(p=0.05)$, especially in females. It was concluded that condyle position in linear tomography at rest position cannot yield TMD diagnosis.
\end{abstract}

DESCRIPTORS: Tomography; Temporomandibular joint disorders; Teen health.

\begin{abstract}
RESUMO: O objetivo deste estudo foi avaliar imagens da ATM de indivíduos portadores e não portadores de distúrbios temporomandibulares (DTM), através da tomografia linear corrigida na posição de repouso. Foram avaliados 217 adolescentes com idade entre 12 e 18 anos através do Índice Craniomandibular (CMI) e de questionário de sintomas subjetivos. Foram selecionados 40 individuos com escores extremos, 20 sem DTM e 20 com DTM, para a formação dos grupos controle e DTM, respectivamente. Os espaços articulares anterior, superior e posterior foram mensurados pela tomografia corrigida, tendo como referência a região de menor comprimento subjetivo, determinando a posição condilar. As médias das distâncias não se correlacionaram com os escores do CMI (p > 0,05). O número de côndilos posteriorizados foi significativamente maior nos pacientes com DTM $(p=0,05)$, principalmente no sexo feminino. Concluímos que a posição condilar na posição de repouso não pode predizer diagnóstico de DTM.
\end{abstract}

DESCRITORES: Tomografia; Transtornos da articulação temporomandibular; Saúde do adolescente.

\section{INTRODUCTION}

The term temporomandibular disorders (TMD) is defined as "collective term embracing a number of clinical problems that involve the masticatory musculature, the temporomandibular joint (TMJ) and associated structures, or both"16. Temporomandibular disorders are considered to be a subclassification of musculoskeletal disorders and are a major source of orofacial pain of non-dental $\operatorname{origin}^{18}$.

TMD in children and adolescents is considered to have a multifactorial etiology $8,17,28$. Because of the difficulty in establishing a precise etiology, TMD is often defined on the basis of signs and symptoms, the most common of which are TMJ and muscle pain, mouth opening limitation, click and crepitation ${ }^{5,12}$.
Whenever a patient presents a suspected TMJ problem, the radiographic examination is part of the patient's complete evaluation ${ }^{1}$. Plain-film radiography and tomography are basic imaging techniques for the assessment of the TMJ.

Observations on condyle position are now being studied and related to TMD; however, its therapeutic implications still remain unclear in the related literature, as well as its importance in the TMD etiology. Previous studies have evaluated the prevalence of anterior, concentric, and posterior condyle position in asymptomatic vol-

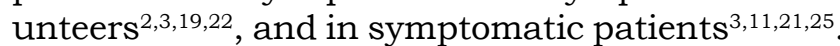
Research has suggested that the measurement of the joint space and the determination of condylar position is of questionable value, given the high

\footnotetext{
* PhD Student in Oral Physiology; **PhD, Professor, Department of Pediatric Dentistry - School of Dentistry of Piracicaba, State University of Campinas.
} 
Pereira LJ, Gavião MBD. Tomographic evaluation of TMJ in adolescents with temporomandibular disorders. Braz Oral Res 2004;18(3):208-14.

variability of condylar position within the fossa in the adult population ${ }^{6,23}$. Although the variability in condylar position in adults may minimize the diagnostic value of the measurement, the assessment of the joint space and condylar position in adolescents may be of value ${ }^{13}$.

The purpose of this study was to determine joint space and condylar position in adolescents with and without TMD viewed in axial linear corrected tomography at mandibular rest position and to correlate these findings to the clinical diagnosis of TMD.

\section{MATERIAL AND METHODS}

The subjects were selected from public schools in the city of Piracicaba/Brazil. The parents and the adolescents were informed of the purpose of the study and they gave their written and verbal consent. The Ethics Committee of the School of Dentistry of Piracicaba approved the research. Adolescents who received any type of orthodontic treatment prior to or during the research examination period were excluded from the study. Initially, the signs of TMD were assessed in 217 adolescents (120 female/97 male) aged 12 to 18 years, according to the Craniomandibular Index (CMI), as described by Fricton, Schiffman ${ }^{9}$ (1986), by two calibrated examiners (kappa $=0.936)$. The $\mathrm{CMI}$ has a 0 to 1 scale that measures tenderness and dysfunction in the stomatognathic system and includes all currently recognized signs of TMJ disorders $^{9,10}$. There are 2 subscales: the Dysfunction Index (DI) and the Palpation Index (PI). The DI is designed to measure limitation in mandibular movement, pain and deviation in movement, TMJ noise, and TMJ tenderness. The PI measures the prevalence of muscle tenderness in the stomatognathic system. Thus, this index separates joint problems from muscle problems.

A self-report questionnaire was used to assess subjective symptoms according to Riolo et al. ${ }^{24}$ (1987), regarding pain in the jaws when in function, unusually frequent headaches (more than once a week), stiffness / tiredness in the jaws, difficulty in opening the mouth wide, grinding teeth, and TMJ sounds. Each question should be answered with "yes" or "no".

After all parameters had been checked, the median score for the CMI was determined. Forty adolescents out of the 217 subjects were selected to dichotomize the data in order to compare "extreme" groups, the lower and upper extremity values being used to compose the control group (10 males/10 females) and the TMD group (10 males / 10 females), respectively. In addition, subjects from the TMD group should present at least one subjective symptom of TMD. The linear tomography was performed in both groups.

\section{Linear tomography}

Corrected linear tomograms (Quint Sectograph, Quint Co., Los Angeles, USA) were obtained with teeth at rest position. The center cut film was used for analysis. Linear measurements, as described by Pullinger, Hollender ${ }^{20}$ (1986), were taken twice by a single examiner of the subjective closest posterior $(\mathrm{P})$, superior $(\mathrm{S})$ and anterior $(\mathrm{A})$ radiological intra-articular spaces. The mean for each space (P, S and A) was used for statistical analysis. The position of the mandibular condyle was described as anterior, concentric, or posterior according to the following equation: linear ratio $=(\mathrm{P}-\mathrm{A}) /(\mathrm{P}+\mathrm{A}) \times 100$, where $\mathrm{P}=$ the closest posterior linear measurement and $\mathrm{A}=$ the closest anterior linear measurement. If the linear ratio was less than -12 , the condyle was considered posterior. If the ratio was between -12 and +12 , the condyle position was considered concentric. If the ratio was greater than +12 , the condyle position was considered anterior.

\section{Statistical analysis}

The values of the distance for anterior, superior and posterior joint spaces measured by tomography were analyzed using the paired $t$-test in both control and TMD groups to verify differences between right and left sides and the non-paired $t$ test to compare distances between groups and genders. Pearson's correlation coefficient and linear regression were determined among the distances obtained in the exams and the CMI, DI and PI. The significance level was set at $\mathrm{p} \leq 0.05$. Fisher's exact test (2-tail) was used to analyze the association between condyle position, groups and gender.

\section{RESULTS}

The mean values obtained for control and TMD groups regarding CMI, DI and PI scores are shown in Table 1.

Table 2 shows the mean distances for the anterior, superior and posterior joint spaces obtained in the linear measurements of tomograms in con- 
Pereira LJ, Gavião MBD. Tomographic evaluation of TMJ in adolescents with temporomandibular disorders. Braz Oral Res 2004;18(3):208-14.

TABLE 1 - Mean values relative to the Dysfunction Index (DI), Palpation Index (PI) e Craniomandibular Index (CMI) scores for control and TMD groups.

\begin{tabular}{l|c|c|c}
\hline \hline \multicolumn{1}{c|}{ Groups } & DI & PI & CMI \\
\hline Control group & $0.056 \pm 0.03^{\mathrm{a}}$ & $0.008 \pm 0.02^{\mathrm{a}}$ & $0.033 \pm 0.01^{\mathrm{a}}$ \\
\hline TMD group & $0.150 \pm 0.10^{\mathrm{b}}$ & $0.321 \pm 0.17^{\mathrm{b}}$ & $0.233 \pm 0.09^{\mathrm{b}}$ \\
\hline
\end{tabular}

Values with different superscript letters differ significantly $(\mathrm{p}<0.05)$. TMD: temporomandibular disorders.

TABLE 2 - Mean ( $\mathrm{mm}$ ) and standard deviation for the articular space measurements in linear tomograms using digital caliper.

\begin{tabular}{c|c|c|c|c|c|c}
\hline \hline \multicolumn{1}{c|}{ Groups } & Tomo ant/r & Tomo ant/1 & Tomo sup/r & Tomo sup/1 & Tomo pos/r & Tomo pos $/ 1$ \\
\hline Control group & $1.90 \pm 0.62$ & $1.58 \pm 0.52$ & $3.89 \pm 1.17$ & $3.71 \pm 1.29$ & $3.66 \pm 1.16$ & $3.23 \pm 1.38$ \\
\hline TMD group & $2.23 \pm 0.85$ & $1.81 \pm 0.69$ & $3.50 \pm 1.55$ & $3.23 \pm 1.45$ & $3.13 \pm 1.56$ & $3.01 \pm 1.08$ \\
\hline \hline
\end{tabular}

Tomo: tomography; ant: anterior; sup: superior; pos: posterior; r: right side; 1: left side (p > 0.05); TMD: temporomandibular disorders.

TABLE 3 - Correlation coefficients $(R)$ and p values between the indexes and the articular space measurements obtained by tomograms.

\begin{tabular}{l|c|c|c|c}
\hline \multicolumn{2}{c|}{} & Tomo ant & Tomo sup & Tomo pos \\
\hline \multirow{2}{*}{ DI } & $\mathrm{R}$ & 0.38272 & -0.09815 & 0.00069 \\
\cline { 2 - 5 } & $\mathrm{p}$ & $0.0148^{*}$ & 0.5468 & 0.9966 \\
\hline \multirow{2}{*}{ PI } & $\mathrm{R}$ & 0.12489 & -0.14913 & -0.04788 \\
\cline { 2 - 5 } & $\mathrm{p}$ & 0.4426 & 0.3584 & 0.8445 \\
\hline \multirow{2}{*}{$\mathrm{CMI}$} & $\mathrm{R}$ & 0.24106 & -0.155404 & -0.02490 \\
\cline { 2 - 5 } & $\mathrm{p}$ & 0.1340 & 0.3395 & 0.8788 \\
\hline \hline
\end{tabular}

Tomo: tomography; ant: anterior; sup: superior; pos: posterior; *p < 0.05. DI: Dysfunction Index; PI: Palpation Index; CMI: Craniomandibular Index.

TABLE 4 - Number of condyles in each position in control and TMD groups.

\begin{tabular}{l|c|c|c}
\hline \hline & Anterior & Concentric & Posterior* \\
\hline Control group & 30 & 9 & 1 \\
\hline TMD group & 25 & 7 & 8 \\
\hline \hline
\end{tabular}

TDM: temporomandibular disorders. ${ }^{*} \mathrm{p}=0.05$.

trol and TMD groups for both sides. There was no statistical difference between right and left sides in both groups. Data were pooled and an individual mean was obtained for each patient to perform the correlation tests. In relation to gender, there was no significant difference in the studied sample.
Table 3 and Figures 1,2 and 3 show the correlation between the obtained values in the images and the indexes. There was a significant positive correlation between the anterior joint space and the DI.

The linear regression showed that signs and symptoms of TMD that determined the index values were not responsible for the variability of tomographic measurements, represented by the $\mathrm{R}^{2}$ of the equations. Despite these coefficients being low, the scatter plots exhibited slightly positive relationships between the anterior joint space and DI, PI and CMI, and a negative relationship between the superior joint space and the indexes. Tables 4 and 5 represent the condylar positions in both groups and the gender distribution of these positions. Each condyle position was determined in isolation. There was a significant difference in the condyle position between control and TMD groups $(p=0.05)$. Data were analyzed with gender differentiation and there was a significant difference between genders for the total sample $(p=0.03)$. When the condyle position of females was evaluated independently, the $p$ value was 0.065 , which may suggest a tendency towards a significant difference in the condyle position for girls between both groups; for boys the $\mathrm{p}$ value was 1.0.

\section{DISCUSSION}

Epidemiologic studies have shown that signs and symptoms of TMD can be found in all age 
FIGURE 1 - Linear regression between the mean values of the articular anterior, superior and posterior spaces obtained by tomography measurements and the Dysfunction Index (DI) $(\mathrm{p}<0.05$ for tomography anterior versus DI).

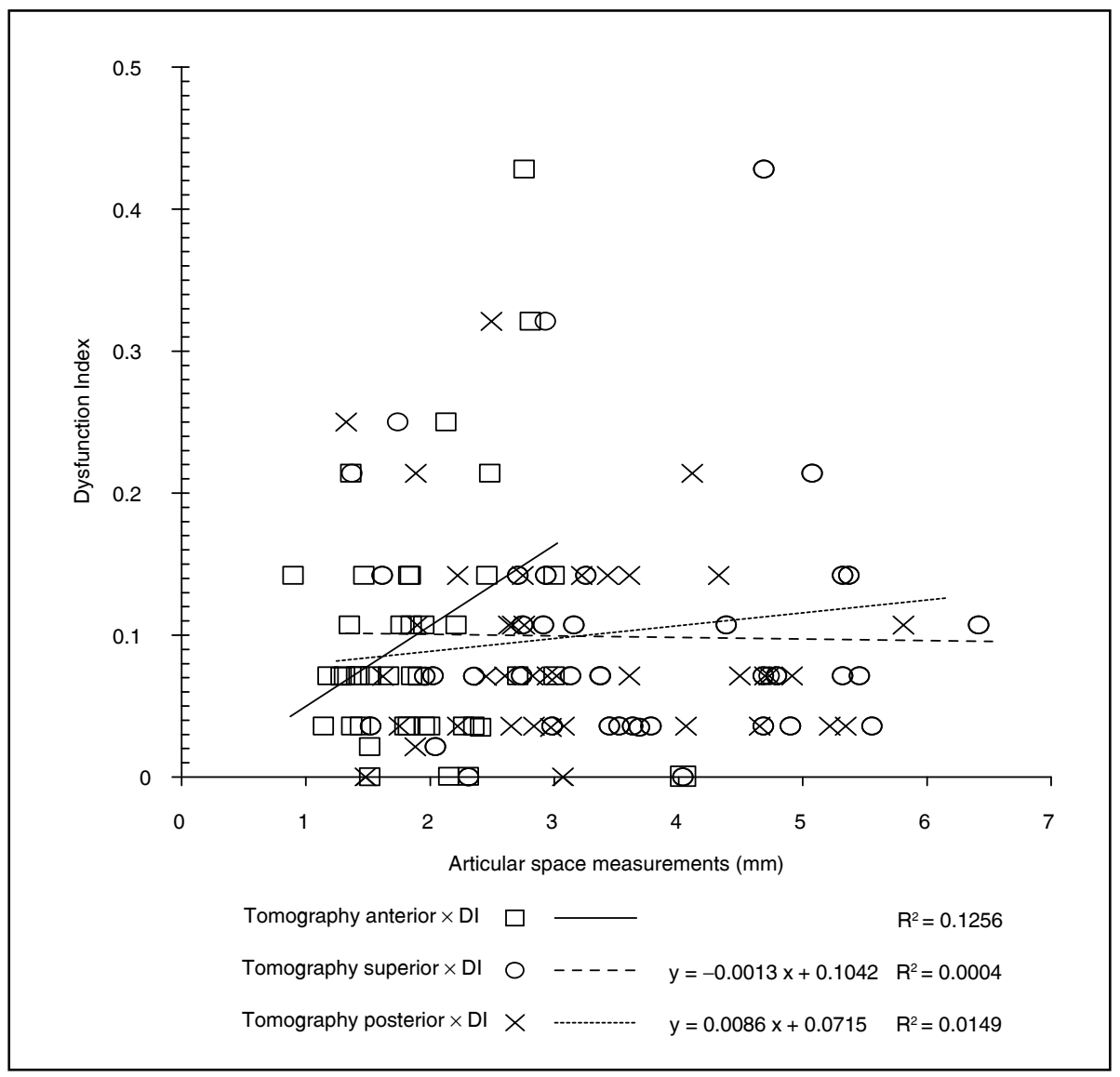

TABLE 5 - Condyle position gender distribution in control and TMD (temporomandibular disorders) groups $(\mathrm{p}=0.03)$.

\begin{tabular}{l|c|c|c|c}
\hline \hline & Girls control & Boys control & Girls TMD & Boys TMD \\
\hline Anterior & $14(70 \%)$ & $16(80 \%)$ & $9(45 \%)$ & $16(80 \%)$ \\
\hline Concentric & $5(25 \%)$ & $4(20 \%)$ & $4(20 \%)$ & $3(15 \%)$ \\
\hline Posterior & $1(5 \%)$ & $0(0 \%)$ & $7(35 \%)$ & $1(5 \%)$ \\
\hline \hline
\end{tabular}

groups ${ }^{26,27,29}$. According to Egermark et al. ${ }^{7}$ (2001) the prevalence is low in young children but increases with age in adolescence up to young adulthood. Since signs and symptoms of TMD involve the muscle of mastication, TMJ and associated structures, it was considered important to determine these variables associated with imaging exams in young subjects, allowing the early diagnosis of structural alterations that could influence the normal growth and of the stomatognathic development system.

The decision to implement a dysfunction index in the present study (CMI) was based on the possibility of objectively measuring the severity of problems in mandibular movements, joint noise, and muscle and joint tenderness, using clearly defined criteria, simple clinical methods and easy scoring. In addition, this index has a good intraand inter-examiner agreement ${ }^{10}$.

With regard to the condyle position in the linear tomograms, it is important to bear in mind that all studies in the related literature refer to the maximal intercuspal measurements. However, most of the time, people generally maintain the mandible at rest position. Thus, the condyle at rest position could cause more cumulative effects on TMJs than the maximal intercuspal position. 
Pereira LJ, Gavião MBD. Tomographic evaluation of TMJ in adolescents with temporomandibular disorders. Braz Oral Res 2004;18(3):208-14.

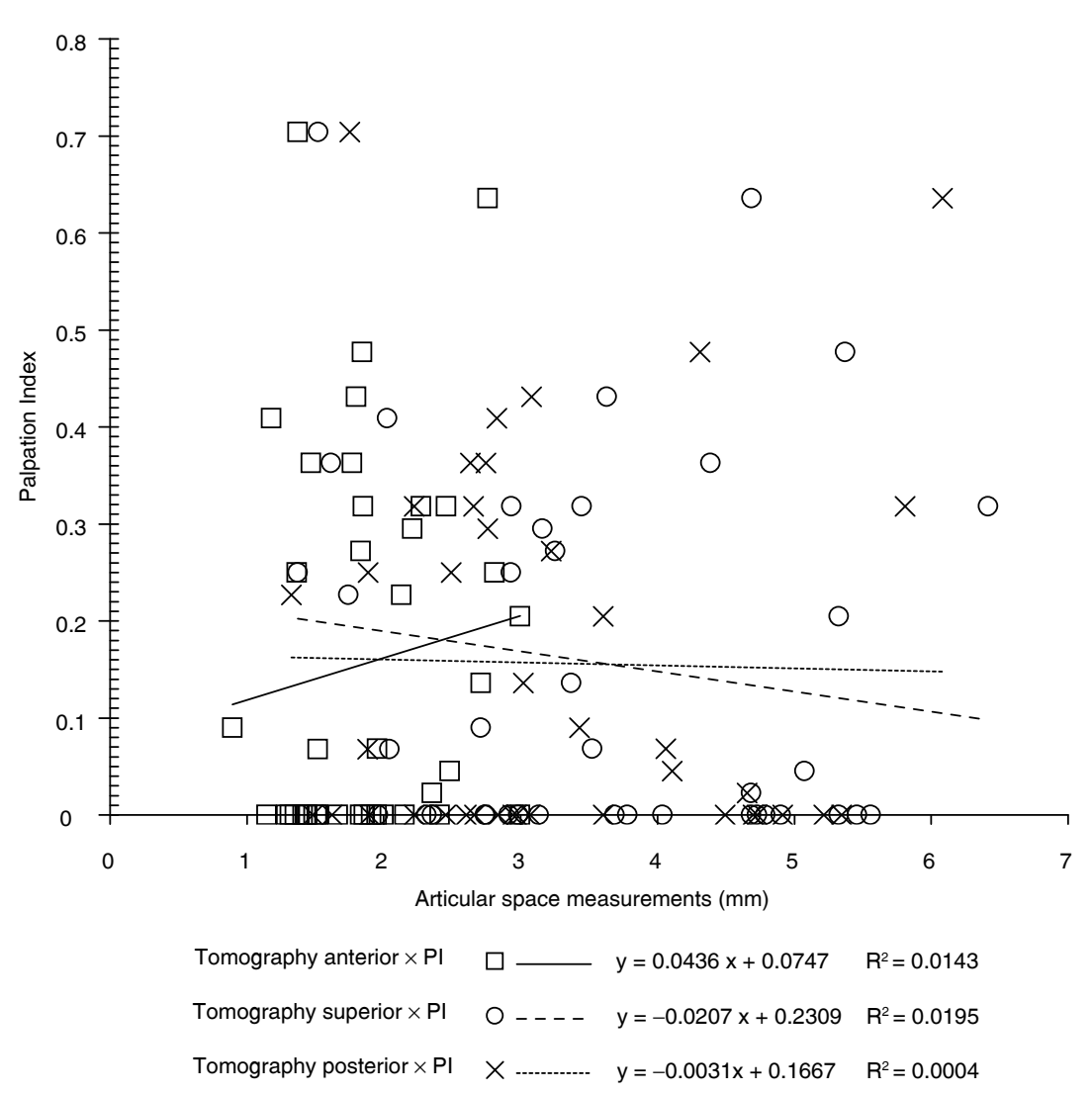

FIGURE 2 - Linear regression between the mean values of the articular anterior, superior and posterior spaces obtained by tomography measurements and the Palpation Index (PI) $(\mathrm{p}>0.05)$.
Bonilla-Aragon et al. ${ }^{4}$ (1999) measured joint spaces in linear tomograms for condyle position determination. Even though there was a significant distal positioning of the condyle in patients with disk displacement, the authors suggested that the position of the condyle was a poor predictor of the presence of internal derangement. In this study, the TMD group also presented a significantly higher number of distally positioned condyles when compared to the control group, corroborating the findings of the above-mentioned authors. However, a higher number of anteriorly positioned condyles were found due to the rest position image used in this study. According to Kordass ${ }^{14}$ (1999) the occlusal pressure transmitted into the joint compartments makes the condyle slide more or less retrocranially whereas the articular disk takes up a more displaced position and a deformed shape, which may change the width of joint spaces in those images in which the soft tissues cannot be well defined.

The joint spaces were also measured in adolescents by Major et al. ${ }^{15}$ (2002) and the values found for the anterior, superior and posterior jointspaces were similar. The minor differences could be explained by the mandible position since the mean age of the adolescents was the same. The authors concluded that as disc displacement increases, the superior joint space decreases, and anterior and posterior joint spaces increase significantly. In this study, such relationships could also be seen as shown in Figures 1 to 3. As the index values (CMI, DI and PI) increase, the anterior joint space also increases and the superior joint space decreases.

In the current study, there were no significant differences between groups and genders regarding the joint space measurements. However, there was a significant difference in condyle position $(p=0.05)$ between groups, indicating a high number of distally positioned condyles in the TMD group. Kinniburgh et al. ${ }^{13}$ (2000) conducted a study considering the condyle position and the joint spaces in adolescents with and without anterior disk displacement. The combined and female samples showed a statistically significant 
FIGURE 3 - Linear regression between the mean values of the articular anterior, superior and posterior spaces obtained by tomography measurements and the Craniomandibular Index (CMI) ( $\mathrm{p}>0.05)$.

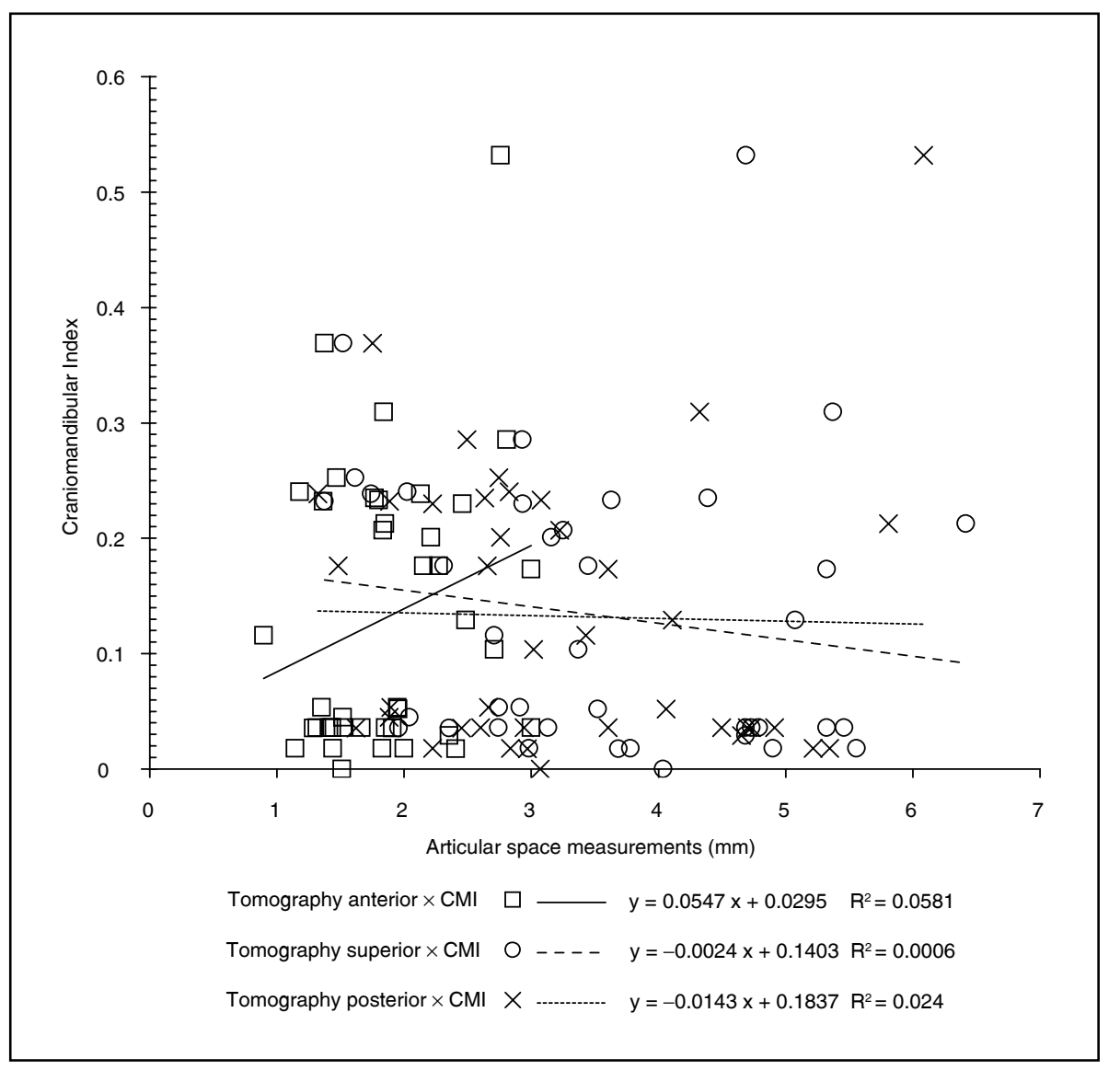

difference between joints with normal and anterior disk position for all joint-space measurements and condylar position. Similarly, male joints displayed significantly different values for anterior and superior joint spaces and condylar position. In this study, when the condyle position was evaluated in differing genders, there was a significant difference $(p=0.03)$ in the total sample. When female joints were analyzed alone, this difference did not occur, with a $\mathrm{p}$ value of 0.065 ; and for the male joints the $\mathrm{p}$ was 1.0 , which may suggest that the difference found in the total sample was due to the greater evidence of distally positioned condyles in females. The differences found between the studies may be corroborated by the fact that those authors had a magnetic resonance diagnosis of internal derangement for the experimental group. However, in this study, the TMD group had only a clinical diagnosis, which may suggest that some patients might have had muscle alterations without internal derangement.

\section{CONCLUSIONS}

Even though there was a significant difference for condyle position determined by tomograms, it cannot be inferred that distally positioned condyles can predict TMD. As there was a great variation in condylar position in both groups, this evaluation was considered inconclusive for TMD diagnosis. This finding implies that changing the position of the condyle based on tomography is not justified as a therapeutic procedure. However, the diagnostic validity of tomography can not be discarded, since it is a reliable exam for osseous diseases.

\section{ACKNOWLEDGMENTS}

This work was supported by the State University of Campinas (UNICAMP) and the Research Foundation of the State of São Paulo (FAPESP \#01/10442-3). We are grateful to Dr. Gláucia Maria Bovi Ambrosano for her advice on the statistical analysis and to Waldeck Ribeiro Moreira and Antonio Custódio Camargo for their advice on tomography. 
Pereira LJ, Gavião MBD. Tomographic evaluation of TMJ in adolescents with temporomandibular disorders. Braz Oral Res 2004;18(3):208-14.

\section{REFERENCES}

1. Berrett A. Radiology of the temporomandibular joint. Dent Clin North Am 1983;27:527-40.

2. Blaschke D, Chase DC. Differences in TMJ condyle-temporal relationships in normal men and women [Abstract 863]. J Dent Res 1984;63:266.

3. Blaschke DD, Blaschke TJ. Normal TMJ bony relationships in centric occlusion. J Dent Res 1981;60:98-104.

4. Bonilla-Aragon H, Tallents RH, Katzberg RW, Kyrkanides $\mathrm{S}$, Moss ME. Condyle position as a predictor of temporomandibular joint internal derangement. J Prosthet Dent 1999;82:205-8.

5. Bronstein SL, Tomasetti BJ, Ryan DE. Internal derangements of the temporomandibular joint: correlation of arthrography with surgical findings. J Oral Surg 1981;39:57284.

6. Dumas AL, Moaddab MB, Willis HB, Homayoun NM. A tomographic study of the condyle/fossa relationship in patients with TMJ dysfunction. J Craniomandibular Pract 1984;2:315-25.

7. Egermark I, Carlsson GE, Magnusson T. A 20-year longitudinal study of subjective symptoms of temporomandibular disorders from childhood to adulthood. Acta Odontol Scand 2001;59:40-8.

8. Egermark-Eriksson I, Carlsson GE, Magnusson T. A long term epidemiologic study of the relationship between occlusal factors and mandibular dysfunction in children and adolescents. J Dent Res 1987;66:67-71.

9. Fricton JR, Schiffman EL. Reliability of a craniomandibular index. J Dent Res 1986;65:1359-64.

10. Fricton JR, Schiffman EL. The craniomandibular index: validity. J Prosthet Dent 1987;58:222-8.

11. Katzberg RW, Keith DA, Ten Eick WR, Guralnick WC. Internal derangements of the temporomandibular joint: an assessment of condylar position in centric occlusion. J Prosthet Dent 1983;49:250-4.

12. Katzberg RW, Westesson PL, Tallents RH, Drake $\mathrm{CM}$. Anatomic disorders of the temporomandibular joint disc in asymptomatic subjects. J Oral Maxillofac Surg 1996;54:147-53.

13. Kinniburgh RD, Major PW, Nebbe B, Glover KE. Osseous morphology and spatial relationships of the temporomandibular joint: comparisons of normal and anterior disc position. Angle Orthod 2000;70:70-80.

14. Kordass B. The temporomandibular joint in video motion - noninvasive image techniques to present the functional anatomy. Anat Anz 1999;181:33-6.

15. Major PW, Kinniburgh RD, Nebbe B, Prasad NG, Glover KE. Tomographic assessment of temporomandibular joint osseous articular surface contour and spatial relationships associated with disc displacement and disc length. Am J Orthod Dentofacial Orthop 2002;121:152-61.

16. McNeill C, editor. Temporomandibular disorders: guidelines for classification, assessment, and management. The
American Academy of Orofacial Pain. Chicago: Quintessence; 1993.

17. Miller VJ. The effect of age on condylar asymmetry in patients with craniomandibular disorders of arthrogenous origin. J Prosthet Dent 1992;67:845-6.

18. Mohl ND, Dixon C. Current status of diagnostic procedures for temporomandibular disorders. J Am Dent Assoc 1994;125:56-64.

19. Pullinger A. The significance of condyle position in normal and abnormal temporomandibular joint function. In: Clark GT, Solberg W, editors. Perspectives in temporomandibular disorders. Chicago: Quintessence; 1987. p. 89103.

20. Pullinger A, Hollender L. Variation in condyle-fossa relationships according to different methods of evaluation in tomograms. Oral Surg Oral Med Oral Pathol 1986;62:71927.

21. Pullinger AG, Solberg WK, Hollander L, Guichet D. Tomographic analysis of mandibular condyle position in diagnostic subgroups of temporomandibular disorders. J Prosthet Dent 1986;55:723-9.

22. Pullinger AG, Solberg WK, Hollander L, Petersson A. Relationship of mandibular condylar position to dental occlusion factors in an asymptomatic population. Am J Orthod Dentofacial Orthop 1987;91:200-6.

23. Ren YF, Isberg A, Westesson PL. Condyle position in the temporomandibular joint. Comparison between asymptomatic volunteers with normal disk position and patients with disk displacement. Oral Surg Oral Med Oral Pathol Oral Radiol Endod 1995;80:101-7.

24. Riolo ML, Brandt D, TenHave TR. Associations between occlusal characteristics and signs and symptoms of TMJ dysfunction in children and young adults. Am J Orthod Dentofacial Orthop 1987;92:467-77.

25. Ronquillo HI, Guay J, Tallents RH, Katzberg RW, Murphy W. Tomographic analysis of mandibular condyle position as compared to arthrographic findings of the temporomandibular joint. J Craniomand Disord 1988;2:5964.

26. Sonmez H, Sari S, Oksak Oray G, Camdeviren H. Prevalence of temporomandibular dysfunction in Turkish children with mixed and permanent dentition. J Oral Rehabil 2001;28:280-5.

27. Thilander B, Rubio G, Pena L, de Mayorga C. Prevalence of temporomandibular dysfunction and its association with malocclusion in children and adolescents: an epidemiologic study related to specified stages of dental development. Angle Orthod 2002;72:146-54.

28. Vanderas AP. Relationship between oral parafunctions and craniomandibular dysfunction in children and adolescents: a review. ASDC J Dent Child 1994;61:378-81.

29. Wahlund K. Temporomandibular disorders in adolescents. Epidemiological and methodological studies and a randomized controlled trial. Swed Dent J Suppl 2003;inside front cover:2-64. 